\title{
Prevalence of anemia and associated factors among the elderly population in South Khorasan, Birjand, 2019
}

\author{
Hakimeh Afaghi ${ }^{1}$, Farshad Sharifi ${ }^{2}$, Mitra Moodi ${ }^{3}$, Gholamreza AnaniSarab ${ }^{4}$, Tooba Kazemi ${ }^{5}$, Elbrahim Miri-Moghaddam ${ }^{6}$, \\ Zoya Tahergorabi ${ }^{7} *$ (D)
}

Received: 21 Jun 2020

Published: 5 Jul 2021

\section{Abstract}

Background: Anemia is a multifactorial and common public health problem in geriatric age groups, especially in developing countries. Therefore, this study was designed to study the prevalence of anemia and associated factors among the elderly population in Birjand, Iran, in 2019.

Methods: This was a cross-sectional approach to the baseline data of the Birjand longitudinal aging study (BLAS) in which 1396 people aged $\geq 60$ years were screened for the presence of anemia based on the World Health Organization (WHO) criteria. For each participant, a standard questionnaire was administered. Furthermore, the height, weight, and body mass index (BMI) were calculated. Blood samples were obtained from each participant for hematological examination. Hemoglobin, hematocrit, and other indices of cell blood count were measured using an automatic cell counter. The prevalence rates were estimated using survey analysis with the weight of Birjand county older population. Univariate and multivariable logistic regression analyses were applied to detect the associated factor with anemia.

Results: The mean age of the participants was $69.73 \pm 7.66$ years. The crude prevalence of anemia was $11.10 \%$, and the agestandardized prevalence based on the standard WHO population $2000-2025$ was equal to $16.78 \%(12.81 \%-21.66 \%)(15.95 \%$ [10.41\%$23.69 \%$ ] in women and $17.32 \%(12.65 \%-23.25 \%)$ in men. Mild and normocytic anemia were the predominant types. The mean hemoglobin, hematocrit, mean cell volume (MCV), mean corpuscular hemoglobin (MCH), and mean corpuscular hemoglobin concentration (MCHC) were lower in women than in men and the mean platelet count in women was higher $(\mathrm{p}<0.001)$. In the final multivariate logistic regression model, only age groups, BMI, fish consumption, and chronic kidney disease (CKD) were related to anemia.

Conclusion: In conclusion, our findings showed the association of anemia with some risk factors and diseases. Anemia in geriatric age groups is often underdiagnosed; hence, identification of subgroups at risk for anemia and its associated risk factors in geriatric groups has a paramount importance in preventing adverse outcomes.

Keywords: Anemia, The Elderly, Population, Prevalence, South Khorasan

Conflicts of Interest: None declared

Funding: Birjand University of Medical Sciences (project No. 455872) and the Elderly Health Research Center of Endocrinology and Metabolism Research Institute in Tehran University of Medical Sciences.

\section{*This work has been published under CC BY-NC-SA 1.0 license. \\ Copyright $\odot$ Iran University of Medical Sciences}

Cite this article as: Afaghi H, Sharifi F, Moodi M, AnaniSarab G, Kazemi T, Miri-Moghaddam E, Tahergorabi Z. Prevalence of anemia and associated factors among the elderly population in South Khorasan, Birjand, 2019. Med J Islam Repub Iran. 2021 (5 Jul);35:86. https://doi.org/10.47176/mjiri.35.86

\section{Introduction}

According to the World Health Organization (WHO) criteria, the elderly is defined as those with the chronolog-

\section{Corresponding author: Dr Zoya Tahergorabi, Z.tahergorabi@bums.com}

1. Student Research Committee, Birjand University of Medical Sciences, Birjand, Iran

2. Elderly Health Research Center, Endocrinology and Metabolism Population Sciences Institute, Tehran University of Medical Sciences, Tehran, Iran

3. Social Determinants of Health Research Center, Birjand University of Medical Sciences, Birjand, Iran

4. Department of Medical Laboratory Sciences, Birjand University of Medicall Sciences, Birjand, Iran

5. Cardiovascular Diseases Research Center, Birjand University of Medicall Sciences, Birjand, Iran

6. Department of Molecular Medicine, Birjand University of Medical Sciences, Birjand, Iran

Medical Toxicology and Drug Abuse Research Center, Birjand University of Medical Sciences, Birjand, Iran

\section{$\uparrow$ What is "already known" in this topic:}

We believe that a comprehensive survey of the prevalence of anemia in the elderly is needed for the following reasons: (1) anemila in the geriatric age groups is a multifactorial condition, which leads to several morbidities and mortality; (2) the socioeconomic status of the studied populationı are heterogenous; and (3) there are different biological risk factors in the studied regions.

\section{$\rightarrow$ What this article adds:}

Our findings showed that the prevalence of anemia was more than $11 \%$ and mild and normocytic anemia was the predominant type. Also, there was an association between anemia and the presence of some risk factors and diseases, such as gender, age, BMI, and CKD. Therefore, the identification of subgroups at risk for anemia and the associated risk factors in geriatric groups is of paramount importance in preventing major age-related disorders. 
ical age of 65 years in most developed countries and 60 years for developing countries (1). The growth of the elderly population all over the world is inevitable. It is estimated that the world population from 1950 to 2050 will increase to 3.7 times, while the number of those aged 60 and above will increase by a factor approximately of 10 ; also, the number of the oldest persons aged 80 and above will increase by a factor of 26 (2).

Anemia is a multifactorial condition and a common public health problem in older adults, particularly in developing countries with a high prevalence in Africa and Southeast Asia. According to the WHO criteria, a hemoglobin value $<12 \mathrm{~g} / \mathrm{dL}$ in women and $<13 \mathrm{~g} / \mathrm{dL}$ in men is defined as anemia in the elderly (3). Blood hemoglobin concentration decreases with aging; thus, the prevalence and incidence of anemia increase with aging (4). However, large studies from Europe and the United States have reported a global prevalence of $\sim 17 \%$ in the cohort study and an overall prevalence of $10 \%$ to $24 \%$ in prospective registry studies in persons older than 65 years $(5,6)$.

Anemia in older adults is often underdiagnosed and the patient is not informed about it because it is considered as an inevitable consequence of aging (7). It is, therefore, associated with inappropriate prognosis, morbidity, and mortality.

There are several risk factors for anemia, including ethnicity, gender, age, nutritional status, poor physical and mental health, gynecological/obstetric disorders history, poor dietary habits, environment, and genetic susceptibility. Body mass index (BMI) is a simple ratio of weight to height and is used for the assessment of nutrition and health status (8).

The most common causes of anemia in the elderly population can be classified as anemia due to chronic infectious disease and chronic inflammatory diseases, such as chronic kidney disease (CKD), collagen disease, and malignancies. Another cause of anemia is nutritional deficiency anemia, such as folate, B12, and iron deficiencies, and the last one includes unexplained anemia (9).

Iron deficiency alone or in combination with other nutrients is more common among nutritional deficiencies and determining its cause is important because blood loss can be due to possible underlying malignancy or ulcer in the gastrointestinal tract and/or arteriovenous malformations (10).

It is noteworthy that $30 \%$ to $50 \%$ of the elderly with anemia have multiple causes of anemia due to being affected by several different pathological conditions and consuming a long list of medications; therefore, the etiology of anemia cannot be determined precisely, and it falls into unexplained anemia (11).

While there are numerous studies conducted on anemia in other age groups, especially children and pregnant women, not many studies have been conducted about anemia in the elderly. This study is the first large work to document the prevalence of anemia in Birjand elderly population. Therefore, this study was designed to study the prevalence of anemia and associated factors among older population residing in Birjand in 2019.

\section{Methods}

This is a cross-sectional approach to the baseline data of the Birjand longitudinal aging study (BLAS). This is an ongoing cohort study in which baseline data were collected from October 2018 to April 2019. This study used a multistage stratified cluster sampling, and the participants were representative of the population aged $\geq 60$ years in Birjand. A comprehensive explanation about sampling and method of data collection has been mentioned elsewhere (12). Inclusion criteria were aged 60 years and over and living in Birjand. The elderly with known hematologic or cancer chemotherapy or radiation therapy, bleeding peptic ulcers, and bleeding colonic carcinoma blood transfusion during the last 6 months were excluded.

Demographic data and past medical history, including history of diabetes, hypertension, CKD and hemodialysis, history of malignancies, connective tissue diseases, liver diseases, and cirrhosis were collected by a trained researcher using an expert-approved questionnaire. Their average food intake was recorded through an interview. An anthropometric measurement, which includes height and weight measurement of people with light clothing and without shoes was conducted according to the National Health and Nutrition Examination Survey (NHENS III) protocol by a trained researcher using a Seca scale (MOD.220 model). Height was measured using a calibrated stadiometer while the participants were standing in a standard position without shoes and any head cap. Hence, BMI was computed using the following standard equation: BMI $=$ weight $(\mathrm{kg}) /$ height $\left(\mathrm{m}^{2}\right)$ and participants were classified into 4 categories according to the WHO cutoff values, including underweight: $\mathrm{BMI}<18.5 \mathrm{~kg} / \mathrm{m}^{2}$; normal: BMI 18.5 to $24.99 \mathrm{~kg} / \mathrm{m}^{2}$; overweight: BMI $25-29.99$ $\mathrm{kg} / \mathrm{m}^{2}$ and obese: $\mathrm{BMI} \geq 30 \mathrm{~kg} / \mathrm{m}^{2}$.

\section{Laboratory Measurement}

Overnight-fasted blood samples were collected from the participants. Three milliliters of venous blood was used for hematologic indexes measurement, including cell blood count $(\mathrm{CBC})$, hemoglobin $(\mathrm{g} / \mathrm{dL})$, hematocrit $(\%)$, mean corpuscular volume $(\mathrm{MCV})(\mathrm{fl})$, mean corpuscular hemoglobin $(\mathrm{MCH})(\mathrm{pg})$, and mean corpuscular hemoglobin concentration (MCHC) (\%). The measurements were done using an automatic cell counter, SysmexKX-21 (Sysmex Corporation Kobe) automated hematology analyzer. Anemia was defined based on blood hemoglobin levels using the WHO criteria (hemoglobin $<12 \mathrm{~g} / \mathrm{dL}$ for females and hemoglobin $<13 \mathrm{~g} / \mathrm{dL}$ for males) (4). The parametric data were presented with mean and standard deviation. The severity of anemia was graded based on the hemoglobin levels, where $<7 \mathrm{~g} / \mathrm{dL}$ was considered as severe anemia, hemoglobin levels $7 \mathrm{~g} / \mathrm{dL} \leq$ hemoglobin $<10$ $\mathrm{g} / \mathrm{dL}$ as moderate anemia, and hemoglobin levels $\geq 10$ and $<12$ in women and $\geq 10$ and $<13$ in men as mild anemia (18). Anemia was classified based on MCV. The MCV $<70 \mathrm{fl}$ was defined as microcytic, 70fl $\geq \mathrm{MCV}<100 \mathrm{fl}$ normocytic and those with MCV $\geq 100 \mathrm{fl}$ as macrocytic anemia (13). 


\section{Ethical Consideration}

This study was approved by the ethical research board of Birjand University of Medical Sciences (Ethical Code $=$ IR.bums.REC.1398.135). All the participants signed an informed consent after being completely informed about the aim and process of the research project.

\section{Statistical Analysis}

The data were analyzed by the Stata software (Version 12, Stata Corp). To compare demographic characteristics and food intake in participants with and without anemia, a $\mathrm{t}$ test, a chi-square, and a Fisher test were used. A survey analysis with weighing for age groups of Birjand county was performed to determine the prevalence of anemia. Age standardization according to WHO population was also performed for reporting of the prevalence of anemia.
The association between anemia and other factors were evaluated using logistic regression models. The final model was constructed by the backward multivariable logistic regression method and all of the variables that had a $P$ value of association higher than. 10 (except sex) were omitted from the model. $\mathrm{P}$ values $<0.05$ were considered as statistically significant.

\section{Results}

The data of 1396 people aged $\geq 60$ years who were enrolled in the BLAS, with completed data about cell blood counting, were considered for analyses. The mean age of the participants was 69.73 (SD, 7.66) years, and $51.4 \%$ $(n=718)$ of the participants were women. The crude prevalence of anemia in this study was $11.10 \%(n=155)$. The BMI was lower in those with anemia than those without

Table 1. General Characteristics and Nutritional Intake of the Participants With and Without Anemia

\begin{tabular}{|c|c|c|c|c|c|c|c|c|}
\hline \multirow{2}{*}{\multicolumn{2}{|c|}{ Variable }} & \multicolumn{2}{|c|}{$\begin{array}{c}\text { Total Population } \\
\mathrm{N}=1396\end{array}$} & \multicolumn{2}{|c|}{$\begin{array}{l}\text { Participant Without Anemia } \\
\qquad \mathrm{N}=1241\end{array}$} & \multicolumn{2}{|c|}{$\begin{array}{l}\text { Participants With Anemia } \\
\qquad \mathrm{N}=155\end{array}$} & \multirow[t]{2}{*}{$\mathrm{p}$} \\
\hline & & $\begin{array}{l}\text { Mean or } \\
\text { Number }\end{array}$ & $\begin{array}{c}\text { SD or } \\
\%\end{array}$ & $\begin{array}{l}\text { Mean or } \\
\text { Number }\end{array}$ & SD or $\%$ & $\begin{array}{l}\text { Mean or } \\
\text { Number }\end{array}$ & $\mathrm{SD}$ or $\%$ & \\
\hline \multicolumn{2}{|c|}{ Age (year) (mean, SD) } & 69.73 & 7.66 & 69.33 & 7.52 & 72.88 & 8.02 & $<0.001$ \\
\hline \multicolumn{2}{|c|}{ Gender (female) $(\mathrm{N}, \%)$} & 718 & 51.43 & 648 & 52.22 & 70 & 45.16 & \\
\hline Education level & Illiterate & 628 & 45.05 & 552 & 44.55 & 76 & 49.03 & \\
\hline \multirow[t]{4}{*}{$(\mathrm{N}, \%)$} & Primary & 438 & 31.42 & 391 & 31.56 & 47 & 30.32 & \\
\hline & High school & 77 & 5.52 & 66 & 5.33 & 11 & 7.10 & 0.490 \\
\hline & Diploma & 137 & 9.83 & 126 & 10.17 & 11 & 7.10 & \\
\hline & Academic & 114 & 8.18 & 104 & 8.39 & 10 & 6.45 & \\
\hline \multirow{4}{*}{$\begin{array}{l}\text { Marital status } \\
(\mathrm{N}, \%)\end{array}$} & Married & 1,141 & 81.73 & 1,015 & 81.79 & 126 & 81.29 & \\
\hline & Single & 6 & 0.43 & 5 & 0.40 & 1 & 0.65 & $0.463 *$ \\
\hline & Widow & 234 & 16.76 & 206 & 16.60 & 28 & 18.06 & \\
\hline & Separated & 15 & 1.07 & 15 & 1.21 & 0 & 0 & \\
\hline \multirow{4}{*}{$\begin{array}{l}\text { Jobs status } \\
(\mathrm{N}, \%)\end{array}$} & Retired & 522 & 37.42 & 464 & 37.42 & 58 & 37.42 & \\
\hline & Employed & 176 & 12.62 & 154 & 12.42 & 22 & 14.19 & 0.922 \\
\hline & House keeper & 628 & 45.02 & 561 & 45.24 & 67 & 43.23 & \\
\hline & Unemployed & 69 & 4.95 & 61 & 4.95 & 8 & 5.16 & \\
\hline \multicolumn{2}{|c|}{ BMI $(\mathrm{Kg} / \mathrm{m} 2)($ mean, $\mathrm{SD})$} & 26.39 & 5.13 & 26.52 & 4.86 & 25.36 & 6.68 & 0.008 \\
\hline \multicolumn{2}{|c|}{$\mathrm{WC}(\mathrm{cm})($ mean, SD) } & 95.23 & 11.83 & 95.66 & 11.60 & $91 . .8$ & 13.08 & $<0.001$ \\
\hline $\begin{array}{l}\text { BMI categorized } \\
\text { WHO }\end{array}$ & $\begin{array}{l}\text { Underweight } \\
(\mathrm{BMI}<18.5)\end{array}$ & 66 & 4.73 & 51 & 4.11 & 15 & 9.68 & \\
\hline \multirow[t]{3}{*}{$(\mathrm{N}, \%)$} & $\begin{array}{l}\text { Ideal body weight } \\
(18.5 \leq \text { BMI }<25)\end{array}$ & 501 & 35.91 & 426 & 34.35 & 75 & 48.39 & $<0.001$ \\
\hline & $\begin{array}{l}\text { Overweight } \\
(25 \leq \mathrm{BMI}<30)\end{array}$ & 536 & 38.42 & 499 & 40.24 & 37 & 23.87 & \\
\hline & Obese $(\mathrm{BMI} \geq 30)$ & 292 & 20.3 & 264 & 21.29 & 28 & 18.06 & \\
\hline \multirow[t]{3}{*}{ Meat consumption } & No use & 193 & 13.84 & 171 & 13.79 & 22 & 14.19 & 0.677 \\
\hline & 1-3 times/Wk & 1,127 & 80.79 & 1000 & 80.65 & 127 & 81.94 & 0.677 \\
\hline & $>4$ times / Wk & 75 & 5.38 & 69 & 5.56 & 6 & 3.87 & 0.677 \\
\hline Poultry & No use & 108 & 7.74 & 98 & 7.90 & 10 & 6.45 & 0.707 \\
\hline \multirow[t]{2}{*}{ consumption } & 1-3 times/Wk & 1,186 & 85.02 & 1,054 & 132 & 132 & 85.16 & 0.707 \\
\hline & $>4$ times / Wk & 101 & 7.24 & 88 & 7.10 & 13 & 8.39 & 0.707 \\
\hline \multicolumn{2}{|c|}{ Fish consumption (Yes) } & 314 & 22.51 & 270 & 21.77 & 44 & 28.39 & 0.063 \\
\hline \multirow[t]{3}{*}{ Milk consumption } & No use & 467 & 33.48 & 421 & 33.95 & 46 & 29.68 & 0.017 \\
\hline & $1-3$ times/Wk & 370 & 26.52 & 339 & 27.34 & 31 & 20.00 & 0.017 \\
\hline & $>4$ times / Wk & 558 & 40.00 & 480 & 38.71 & 78 & 50.32 & 0.017 \\
\hline \multirow{3}{*}{$\begin{array}{l}\text { Cheese consump- } \\
\text { tion }\end{array}$} & No use & 168 & 12.04 & 147 & 11.85 & 21 & 13.55 & 0.743 \\
\hline & 1-3 times/Wk & 211 & 15.13 & 186 & 15.00 & 25 & 16.13 & 0.743 \\
\hline & $>4$ times / Wk & 1,016 & 72.83 & 907 & 73.15 & 109 & 70.32 & 0.743 \\
\hline \multirow[t]{3}{*}{ Fruits consumption } & Zero or once/Wk & 96 & 6.88 & 83 & 6.69 & 13 & 8.39 & 0.723 \\
\hline & 2-4 times/Wk & 980 & 70.25 & 872 & 70.32 & 108 & 69.68 & 0.723 \\
\hline & $>4$ times / Wk & 319 & 22.87 & 285 & 22.98 & 34 & 21.94 & 0.723 \\
\hline \multirow[t]{3}{*}{ Vegetable eating } & No use & 307 & 22.02 & 261 & 21.07 & 46 & 29.68 & 0.044 \\
\hline & $1-3$ times/Wk & 626 & 44.91 & 566 & 45.68 & 60 & 38.71 & 0.044 \\
\hline & $>4$ times / Wk & 461 & 33.07 & 412 & 33.25 & 49 & 31.61 & 0.044 \\
\hline \multicolumn{2}{|c|}{ Digestive problems (Yes) } & 297 & 21.31 & 260 & 20.98 & 37 & 23.87 & 0.470 \\
\hline \multicolumn{2}{|c|}{ Hemorrhoid (Yes) } & 72 & 5.16 & 62 & 5.00 & 10 & 6.45 & 0.731 \\
\hline Cancer (Yes) & & 1,359 & 99.12 & 1,211 & 99.02 & 148 & 100.00 & 0.226 \\
\hline
\end{tabular}

*Fisher exact test; SD: standard deviation; BMI: body mass index; Wk: week. 
anemia $(25.36$ vs $26.52 ; p=0.008)$. The frequency of selfreported CKD was higher in participants with anemia than those who did not have anemia (Table 1). The intake of different types of food was assessed as well. In participants with anemia, the rate of using milk per week was higher than those without anemia $(\mathrm{p}=0.017)$, and the rate of using vegetables was lower in those with anemia than those without anemia (Table 1).

The mean of hemoglobin, hematocrit, red blood cell count (RBC), $\mathrm{MCV}, \mathrm{MCH}$, and $\mathrm{MCHC}$ was lower in women than in men $(\mathrm{p}<0.001)$. However, the mean platelet count in women was higher than in men $\left(240 \times 10^{3} / \mathrm{m}^{3}\right.$ in women than $206 \times 10^{3} \mathrm{~m}^{3}$ in men) (Table 2).

The prevalence of anemia was more common in older men $(12.54 \% ; n=85)$ than older women $(9.75 \% ; n=70)$. After considering the weight and performing a standardization for the WHO population, the prevalence of anemia in the studied population was calculated as $16.78 \%,(95 \%$ CI, 12.82\%-21.66\%). The WHO age-standardized prevalence of anemia in women was estimated as $15.96 \%(95 \%$ CI, $10.41 \%-23.69 \%)$ and $17.32 \%$ (95\% CI, $12.65 \%$ $23.25 \%$ ) in men. Overall, the age-standardized prevalence of anemia was higher in older age groups who had a low body weight than those who were in younger groups and had higher BMI groups (Table 3). More than 90\% of the participants with anemia were classified as having a mild anemia according to the WHO definition of anemia and less than $1 \%$ of the studied population were classified as having severe anemia. Moreover, the participants were assessed in terms of $\mathrm{MCV}$ and were categorized into groups with microcytic, normocytic, and macrocytic RBC. Only $1.9 \%$ of the participants with anemia and $0.75 \%$ of those who had no anemia had microcytosis (Fig. 1).

In univariable logistic regression models, the associa-

Table 2. Hematological Indices in Participants and Both Genders

\begin{tabular}{|c|c|c|c|c|c|c|c|}
\hline \multirow[t]{2}{*}{ Hematologic indices } & \multicolumn{2}{|c|}{$\begin{array}{c}\text { Total } \\
\mathrm{N}=1396\end{array}$} & \multicolumn{2}{|c|}{$\begin{array}{c}\text { Female } \\
\mathrm{N}=718\end{array}$} & \multicolumn{2}{|c|}{$\begin{array}{c}\text { Male } \\
\mathrm{N}=678\end{array}$} & \multirow[t]{2}{*}{$\bar{p}$} \\
\hline & Mean & $95 \%$ CI mean & Mean & $95 \%$ CI mean & Mean & $95 \%$ CI mean & \\
\hline Hemoglobin (g/dl) & 14.22 & $14.13-14.31$ & 13.57 & $13.47-13.67$ & 14.91 & $14.79-15.03$ & $<0.001$ \\
\hline $\mathrm{HCT}(\%)$ & 41.68 & $41.46-41.91$ & 40.17 & $39.90-40.43$ & 43.30 & $42.98-43.61$ & $<0.001$ \\
\hline $\mathrm{RBC} \times 10^{6} / \mathrm{mm}^{3}$ & 4.76 & $4.71-4.82$ & 4.65 & $4.57-4.73$ & 4.90 & $4.83-4.97$ & $<0.001$ \\
\hline $\mathrm{WBC} \times 10^{3} / \mathrm{mm}^{3}$ & 6.27 & $6.19-6.36$ & 6.20 & $6.08-6.31$ & 6.36 & $6.23-6.49$ & 0.045 \\
\hline $\operatorname{MCV}(\mathrm{fl})$ & 85.89 & $85.60-86.17$ & 85.26 & $84.87-85.64$ & 86.56 & $86.15-86.97$ & $<0.001$ \\
\hline $\mathrm{MCH}(\mathrm{pg})$ & 29.34 & $29.19-29.50$ & 28.91 & $28.65-29.16$ & 29.81 & $29.64-29.98$ & $<0.001$ \\
\hline $\mathrm{MCHC}(\%)$ & 34.10 & $34.02-34.19$ & 33.78 & $33.67-33.89$ & 34.44 & $34.32-34.56$ & $<0.001$ \\
\hline Platelet $\times 10^{3} / \mathrm{mm}^{3}$ & 228.61 & $224.98-232.25$ & 245.10 & $240.00-250.21$ & 211.01 & $206.20-215.82$ & $<0.001$ \\
\hline \multicolumn{8}{|c|}{$\begin{array}{l}\text { CI: confidence interval, HCT: hematocrit, RBC: Red blood cell count, WBC: White blood cell count, MCV: mean corpuscular vollume, MCH: mean corpuscular hemo } \\
\text { globin, MCHC: mean corpuscular hemoglobin concentration. }\end{array}$} \\
\hline \multicolumn{8}{|c|}{ Table 3. Age Standardized Prevalence of Anemia Based on WHO Population } \\
\hline \multirow[t]{2}{*}{ Prevalence of anemia } & & \multicolumn{2}{|c|}{ Total population $\mathrm{N}=1396$} & \multicolumn{2}{|c|}{ Female $\mathrm{N}=718$} & \multicolumn{2}{|c|}{ Male $\mathrm{N}=678$} \\
\hline & & $\begin{array}{c}\text { Point } \\
\text { estimation } \\
\end{array}$ & $\begin{array}{c}95 \% \text { CI Point } \\
\text { estimation }\end{array}$ & $\begin{array}{c}\text { Point } \\
\text { estimation } \\
\end{array}$ & $\begin{array}{c}95 \% \text { CI Point } \\
\text { estimation }\end{array}$ & $\begin{array}{c}\text { Point } \\
\text { estimation } \\
\end{array}$ & $\begin{array}{c}95 \% \text { CI Point } \\
\text { estimation }\end{array}$ \\
\hline \multirow{5}{*}{$\begin{array}{l}\text { Total prevalence of } \\
\text { Prevalence of ane- } \\
\text { mia based on BMI } \\
\text { groups }(\%)\end{array}$} & emia & 16.78 & $12.81-21.66$ & 15.96 & $10.41-21.69$ & 17.32 & $12.65-23.25$ \\
\hline & LBW & 23.14 & $14.11-35.55$ & 8.67 & $1.25-41.66$ & 30.30 & $18.50-45.44$ \\
\hline & IBW & 14.34 & $11.50-17.72$ & 13.94 & $9.69-19.65$ & 14.60 & $11.05-19.05$ \\
\hline & Overweight & 6.44 & $4.63-8.89$ & 7.43 & $4.80-11.34$ & 16.28 & $7.08-33.18$ \\
\hline & Obese & 9.73 & $6.69-13.92$ & 10.36 & $6.68-15.73$ & 5.34 & $3.25-8.67$ \\
\hline \multirow{6}{*}{$\begin{array}{l}\text { Prevalence of ane- } \\
\text { mia based on age } \\
\text { groups }(\%)\end{array}$} & $60-64$ years & 6.57 & $4.57-9.36$ & 7.76 & $4.94-11.98$ & 8.07 & $3.99-15.65$ \\
\hline & $65-69$ years & 8.58 & $603-1206$ & 7.10 & $4.33-11.46$ & 10.07 & $6.16-16.04$ \\
\hline & $70-74$ years & 13.64 & $10.00-18.32$ & 10.43 & $6.02-17.49$ & 16.89 & $11.67-23.82$ \\
\hline & $75-79$ years & 17.29 & $12.28-23.79$ & 16.09 & $9.76-25.37$ & 18.52 & $11.48-28.49$ \\
\hline & $80-84$ years & 14.54 & $9.16-22.32$ & 11.36 & $4.80-24.56$ & 17.39 & $10.14-28.19$ \\
\hline & $85+$ years & 22.53 & $13.35-35.43$ & 24.00 & $11.19-44.18$ & 20.51 & $10.60-35.98$ \\
\hline
\end{tabular}

CI: confidence interval; LBW: low body weight; IBW: Ideal body weight; BMI: body mass index.

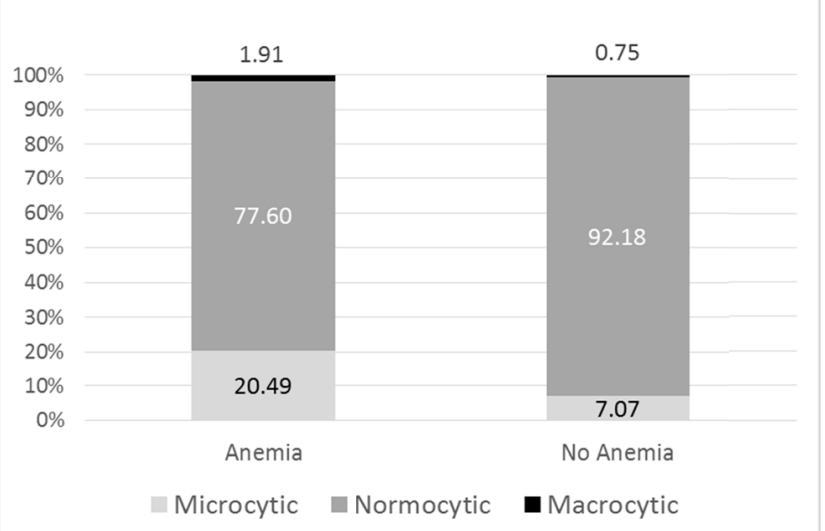

Fig. 1. Frequency of microcytosis, normocytic, and macrocytosis in the participants based on MCV with and without anemia (age-standardized based on WHO population). 
tion between anemia and demographic, anthropometric dietary, and self-reported history of disorders was assessed. The odds ratios for anemia in those aged 85 years old were $3.95 \%$ higher than those aged $60-64$ years and older. Furthermore, the odds ratio of anemia in overweight and obese participants was $75 \%$ and $65 \%$ less than those who were underweight, respectively (OR of anemia, 0.25 ; CI $95 \%, 0.13-0.40$ in overweight individuals and odds ratio equal to 0.35 ; CI $95 \%, 0.17-0.70$ for obese participants). Participants who drank milk 4 times or more per week had odds equal to 1.49 of anemia compared to those who did not drink milk at all. Those who consumed vegetables had $40 \%$ lower odds of anemia than those who did not consume vegetables at all. Only self-reported CKD was associated with anemia (OR, 3.38) in univariable models and other diseases were not related (Table 4). We used the backward method for assessing the factors that were related to anemia (the cutoff of $p>0.10$ ) and sex was preserved in the model because a strong relationship between anemia and gender was reported in other studies. In the final multivariable logistic regression model, only age (OR increased with aging), BMI (ORs was significantly lower in those who were overweight and obese compared to those who had low body weight), fish consumption (the OR was 1.52 in consumers than nonconsumers), and CKD were related to anemia (Table 4).

\section{Discussion}

The crude prevalence of anemia in this study was more than $11 \%$ and the WHO age-standardized prevalence of anemia was about $16.8 \%$. To our knowledge, several studies in the literature have reported the prevalence of anemia in the elderly, but there are a few large-scale populationbased studies with a high inclusion rate.

The prevalence of anemia in our study is similar to a prospective population-based study in 2010 on 8744 elderly aged 65 years or older in Biella (Italy) according to the WHO criteria with a prevalence rate of $11.8 \%$ (10). Also, there is a low prevalence in Mexican and Brazilian elderlies, 7.7\% (14), and a high prevalence rate in Kashmir, $77.5 \%$ (15). The possible reasons for inconsistencies might be differences in the demographic composition of the participated population and most of these studies did not report the age-standardized prevalence. Also, the prevalence of anemia changes by the definitions and the differences in cutoff points for the selection of older age in developed and developing countries.

In our study, the age-standardized prevalence of anemia was about $17.3 \%$ in men and near $16 \%$ in women. This is in accordance with the study by Kaur et al (2014) who

Table 4. Associated Factor with Anemia in Univariate and Multivariable Logistic Regression Models

\begin{tabular}{|c|c|c|c|c|c|c|c|}
\hline \multicolumn{5}{|c|}{ Univariate Models } & \multicolumn{3}{|c|}{ Multivariate Models } \\
\hline \multirow{2}{*}{\multicolumn{2}{|c|}{ Variables }} & Odds & $95 \%$ CI Odds & $\mathrm{p}$ & Odds & $95 \% \mathbb{C I}$ Odds & $\mathrm{p}$ \\
\hline & & Ratio & Ratio & & Ratio & Ratio & \\
\hline \multicolumn{2}{|c|}{ Gender (male/female) } & 1.33 & $0.95-1.86$ & 0.098 & 1.13 & $0.77^{\prime}-1.67$ & 0.534 \\
\hline \multirow[t]{6}{*}{ Age group } & $60-64$ years & \multicolumn{6}{|c|}{ Reference group } \\
\hline & $65-69$ years & 1.28 & $0.75-2.19$ & 0.362 & 1.13 & $0.65-1.96$ & 0.658 \\
\hline & $70-74$ years & 2.31 & $1.38-3.87$ & 0.002 & 1.87 & $1.101-3.19$ & 0.021 \\
\hline & $75-79$ years & 2.94 & $1.69-5.12$ & 0.000 & 2.51 & $1.42-4.43$ & 0.002 \\
\hline & $80-84$ years & 2.50 & $1.31-4.75$ & 0.005 & 1.66 & $0.84-3.28$ & 0.141 \\
\hline & $85+$ years & 3.95 & $1.95-8.00$ & 0.000 & 2.65 & $1.26-5.57$ & 0.010 \\
\hline \multirow[t]{4}{*}{ BMI } & Low body weight & \multicolumn{6}{|c|}{ Reference group } \\
\hline & Ideal body weight & 0.60 & $0.32-1.12$ & 0.108 & 0.60 & $0.34-1.25$ & 0.196 \\
\hline & Overweight & 0.25 & $0.13-0.49$ & 0.001 & 0.30 & $0.15-0.60$ & 0.001 \\
\hline & Obese & 0.35 & $0.17-0.70$ & 0.003 & 0.46 & $0.22-0.98$ & 0.044 \\
\hline \multirow[t]{3}{*}{ Meat } & No Use & \multicolumn{6}{|c|}{ Reference group } \\
\hline & 1-3 times per week & 0.99 & $0.61-1.60$ & 0.958 & & & \\
\hline & $4+$ times per week & 0.68 & $0.26-1.74$ & 0.417 & & & \\
\hline \multirow[t]{3}{*}{ Chicken } & No use & \multicolumn{6}{|c|}{ Reference group } \\
\hline & 1-3 times per week & 1.23 & $0.62-2.41$ & 0.552 & & & \\
\hline & $4+$ times per week & 1.45 & $0.60-3.47$ & 0.406 & & & \\
\hline \multicolumn{2}{|c|}{ Fish consumption (User/Non-user) } & 1.42 & $0.98-2.07$ & 0.064 & 1.52 & $1.02-2.27$ & 0.040 \\
\hline \multirow[t]{3}{*}{ Milk consumption } & No use & \multicolumn{6}{|c|}{ Reference group } \\
\hline & 1-3 times per week & 0.84 & $0.52-1.35$ & 0.465 & 0.87 & $0.53-1.43$ & 0.582 \\
\hline & $4+$ times per week & 1.49 & $1.01-2.19$ & 0.044 & 1.46 & $0.96-2.20$ & 0.074 \\
\hline Cheese consump- & No use & \multicolumn{6}{|c|}{ Reference group } \\
\hline \multirow{2}{*}{ tion } & 1-3 times per week & 0.94 & $0.51-1.75$ & 0.847 & & & \\
\hline & $4+$ times per week & 0.84 & $0.51-1.38$ & 0.497 & & & \\
\hline \multirow[t]{3}{*}{ Egg consumption } & No use & \multicolumn{6}{|c|}{ Reference group } \\
\hline & 1-3 times per week & 1.00 & $0.59-1.70$ & 0.993 & & & \\
\hline & $4+$ times per week & 0.74 & $0.38-1.45$ & 0.382 & & & \\
\hline \multirow[t]{3}{*}{ Fruit consumption } & Use $\leq$ one serve /day & \multicolumn{6}{|c|}{ Reference group } \\
\hline & $2-4$ serves /day & 0.79 & $0.43-1.47$ & 0.456 & & & \\
\hline & 4 serves or more & 0.76 & $0.38-1.51$ & 0.436 & & & \\
\hline \multirow{3}{*}{$\begin{array}{l}\text { Vegetables } \\
\text { consumption }\end{array}$} & No use & \multicolumn{6}{|c|}{ Reference group } \\
\hline & 1-3 times per week & 0.60 & $0.40-0.90$ & 0.015 & 0.68 & $0.42-1.05$ & 0.085 \\
\hline & more than 3 times & 0.67 & $0.44-1.04$ & 0.074 & 0.77 & $0.491-1.31$ & 0.277 \\
\hline \multicolumn{2}{|c|}{ Hemorrhoid (Yes/No) } & 1.31 & $0.66-2.61$ & 0.444 & & & \\
\hline \multicolumn{2}{|c|}{ GI Problem (Yes/No) } & 1.18 & $0.80-1.75$ & 0.408 & & & \\
\hline \multicolumn{2}{|c|}{ CKD (Yes/No) } & 3.38 & $1.69-6.76$ & 0.001 & 3.60 & $1.75-7.42$ & 0.001 \\
\hline
\end{tabular}

CI: Confidence interval, BMI: Body mass index, GI: Gastrointestinal, CKD: Chronic kidney disease 
studied 2540 people aged 60 years and older. Their results showed that there was more anemia in men than in women (58\% vs $42 \%$ ) (16).

In contrast, Obaidely et al found that anemia is more prevalent in elderly women than in elderly men (40.6\% vs $28.7 \%$ ) who lived in nursing homes in Qatar (17).

A sex difference in hemoglobin levels was found in both animals and humans, which might be related to the effect of sex hormones (estrogen and testosterone) on erythropoiesis. However, erythropoietin levels in men and premenopausal and postmenopausal women are the same. Therefore, the hormone effect must take place possibly in another location like kidney rather than bone marrow as documented in a previous study (18). Erythropoietin is a glycoprotein growth factor mainly produced by kidneys in a hypoxic condition. Since estrogen and testosterone have vasodilation and vasoconstriction effects in renal vasculature, respectively, they may cause different hematocrit in arterioles, capillaries, and venules as well as different oxygen delivery rates per red blood cell (18). We found a higher prevalence of anemia in older men than in older women, while the mean hemoglobin level in men was higher than in women. In other words, we have a discrepancy between hemoglobin level and anemia that is justified by a different definition of anemia in different genders.

Our results showed that the prevalence of anemia increased with aging in both genders.

Our results support those of the study of Orces conducted on older adults residing in the Coastal and Andes mountains in Ecuador (13). Like most organs and tissues, hematopoietic aging is evident as a reduced adaptive immune system, which induces immune dysfunction and increased incidence of myeloproliferative diseases, including myelodysplastic syndromes (MDS) and increased anemia (19). A cellular and molecular damage for hematopoietic stem cells (HSC) with aging has been shown as both cell-intrinsic and cell-extrinsic mechanisms (19). Cell-extrinsic mechanisms are the alterations in bone marrow niche composition, including an increase in adipose tissue and a decrease in overall hematopoietic tissue. Cell-intrinsic mechanisms include alterations in transcriptional profiles and changes in the global epigenetic profile. Furthermore, the humoral control of erythropoiesis changes with aging could take place because of either an increased erythropoietin demand in anemic older adults that do not meet the increased demand or as a decreased capacity of renal hormone production, which can lead to the development of anemia (20).

In this study, those with low body weight had a higher standardized rate of anemia than the other groups of WHO BMI categorized groups. BMI is frequently used as a measure of nutritional and health status, and low BMI in some previous studies has been identified as an independent risk factor for anemia in older adults (8). A study showed strong associations between BMI and hemoglobin level and anemia (21). However, Lee et al found that none of the anthropometric indices were good indicators of the hemoglobin level (22). A low BMI may be associated with anemia due to malnutrition and malabsorption of essential micronutrients, such as iron, vitamin B12, folate, zinc, and vitamin D, as many studies have shown that diet modification and proper nutrition are related to improvement in anemia $(23,24)$. It is noteworthy to mention that nutritional deficiency is also associated with some factors, including cultural beliefs and religious prohibitions and socioeconomic factors (25).

In this context, in our study, participants with anemia used more milk per week than those without anemia. Anemia in these people may be due to a decrease in gastric acid secretion, which can decrease the absorption of iron and vitamin B12 in aged people. Furthermore, lactose intolerance is common in elderly individuals and is accompanied by abdominal distention, flatulence, diarrhea, and pain after ingestion of dairy products (26).

Self-reported chronic kidney disease was associated with 3.4 higher risk of anemia. Our results are in agreement with Orcs on older adults residing in the Coastal and Andes mountains in Ecuador (13). However, our results are in contrast with Nalado et al who tested $353 \mathrm{CKD}$ adult patients in Charlotte Maxeke Johannesburg Academic hospital (27). Low hemoglobin levels in the elderly with CKD or renal anemia is a common problem. The humoral control mechanism of erythropoiesis is mainly associated with erythropoietin; hence, erythropoietin deficiency is accepted as a leading cause of renal anemia. Accordingly, the kidney is considered as the main source of erythropoietin in response to a hypoxic condition (28). Different studies have shown conflicting results about erythropoietin levels in elderly participants, possibly due to comorbidities accompanying in aged people (29), including diabetes as the most common cause of CKD. Other possible causes for renal anemia are the accumulation of uremic toxins that inhibits erythropoiesis and reduces red blood cell (RBC) lifespan due to the uremic environment in CKD patients.

Also, $77.6 \%$ of anemic individuals in our study were normocytic based on MCV results and this kind of anemia is associated with chronic diseases. CKD was only associated with anemia in this study among other studied diseases, including cancer and digestive diseases. Anemia due to chronic disease or inflammation is a common consequence of chronic diseases, including infections, inflammatory conditions, and malignancies $(17,30)$.

There are some limitations in this study. First, since this study had a cross-sectional design, it was not possible to determine the direct associations and consequently the causations. Second, it was not possible to measure the markers related to the causes of anemia, including interleukin (IL-6), ferritin, folate, and vitamin B12.

\section{Conclusion}

In conclusion, the prevalence of anemia among the studied geriatric groups was found to be an important public health problem with the most common type of normocytic. Our findings showed the association of anemia with some risk factors and diseases, such as gender, age, BMI, and CKD. Thus, an appropriate clinical approach is essential to treat anemia in the eldlerly because anemia often remains underreported and is inadequately investigated, 
particularly the mild form.

\section{Acknowledgement}

We are grateful for the financial support of Birjand University of Medical Sciences (project No. 455872) and the Elderly Health Research Center of Endocrinology and Metabolism Research Institute in Tehran University of Medical Sciences.

\section{Conflict of Interests}

The authors declare that they have no competing interests.

\section{References}

1. Bayuo J, Botchway AE. Burns among older persons: A narrative review. Burns Open. 2017 Jul 1;1(1):2-8.

2. Noroozian M. The elderly population in Iran: an ever growing concern in the health system. Iran J Psychiatry Behav Sci. 2012;6(2):1-6.

3. Melku M, Asefa W, Mohamednur A, Getachew T, Bazezew B, Workineh M. Magnitude of Anemia in Geriatric Population Visiting Outpatient Department at the University of Gondar Referral Hospital, Northwest Ethiopia: Implication for Community-Based Screening. Curr Gerontol Geriatr Res. 2018;2018:9869343.

4. Silva EC, Roriz AK, Eickemberg M, Mello AL, Cortes EB, Feitosa CA, et al. Correction: Factors Associated with Anemia in the Institutionalized Elderly. PloS One. 2016;11(12):e0169377.

5. Stauder R, Valent P, Theurl I. Anemia at older age: etiologies, clinical implications, and management. Blood. 2018;131(5):505-14.

6. Stauder R, Thein SL. Anemia in the elderly: clinical implications and new therapeutic concepts. Haematologica. 2014;99(7):1127-30.

7. Tettamanti M, Lucca U, Gandini F, Recchia A, Mosconi P, Apolone $\mathrm{G}$, et al. Prevalence, incidence and types of mild anemia in the elderly: the "Health and Anemia" population-based study. Haematologica. 2010;95(11):1849-56

8. Hausman DB, Johnson MA, Davey A, Poon LW. Body mass index is associated with dietary patterns and health conditions in georgia centenarians. J Aging Res. 2011;2011:138015.

9. Busti F, Campostrini N, Martinelli N, Girelli D. Iron deficiency in the elderly population, revisited in the hepcidin era. Front Pharmacol 2014;5:83.

10. Camaschella C. Iron-deficiency anemia. N Engl J Med. 2015:372(19): 1832-43.

11. Andres E, Serraj K, Federici L, Vogel T, Kaltenbach G. Anemia in elderly patients: new insight into an old disorder. Geriatr Gerontol Int 2013;13(3):519-27.

12. Moodi M, Firoozabadi MD, Kazemi T, Payab M, Ghaemi K, Miri MR, et al. Birjand longitudinal aging study (BLAS): the objectives, study protocol and design (wave I: baseline data gathering). J Diabetes Metab Disord. 2020:1-9.

13. Orces CH. Prevalence of Anemia among Older Adults Residing in the Coastal and Andes Mountains in Ecuador: Results of the SABE Survey. Curr Gerontol Geriatr Res 2017;2017:4928786.

14. Corona LP, Duarte YA, Lebrao ML. Prevalence of anemia and associated factors in older adults: evidence from the SABE Study. Rev Saude Revista. 2014;48(5):723-431.

15. Hilal N, Mushtaq A. Prevalence of anemia in geriatric population of Kashmir: A hospital based study. Ann Med Physiol. 2017.

16. Kaur H, Piplani S, Madan M, Paul M, Rao S. Prevalence of anemia and micronutrient deficiency in elderly. Int $\mathrm{J}$ Med Dent Sci. 2015;3(1):296-302.

17. Obaidely M, Nadukkandiyil N, Asim M, Najma F, Hamad H. Prevalence and Impact of Anemia Among Elderly Population in Qatar: A Cross Sectional Study. J Gerontol Geriatr Res. 2017;6(421):2.

18. Murphy WG. The sex difference in haemoglobin levels in adults mechanisms, causes, and consequences. Blood Rev. 2014;28(2):41-7.

19. Latchney SE, Calvi LM. The aging hematopoietic stem cell niche: Phenotypic and functional changes and mechanisms that contribute to hematopoietic aging. Semin Hematol. 2017;54(1):25-32.

20. Vanasse GJ, Berliner N. Anemia in elderly patients: an emerging problem for the 21st century. Am Soc Hematol Educ Program.
2010;2010:271-5.

21. Qin Y, Melse-Boonstra A, Pan X, Yuan B, Dai Y, Zhao J, et al. Anemia in relation to body mass index and waist circumference among Chinese women. Nutr J. 2013;12:10.

22. Lee BJ, Kim JY. Identification of hemoglobin levels based on anthropometric indices in elderly Koreans. PLoS One. 2016 Nov $3 ; 11(11): \mathrm{e} 0165622$

23. Contreras-Manzano A, Cruz Vdle L, Villalpando S, Rebollar R, Shamah-Levy T. Anemia and iron deficiency in Mexican elderly population: Results from the Ensanut 2012. Salud Publica Mex. 2015;57(5):394-402

24. Dangour AD, Allen E, Clarke R, Elbourne D, Fasey N, Fletcher AE, et al. A randomised controlled trial investigating the effect of vitamin B12 supplementation on neurological function in healthy older people: the Older People and Enhanced Ne:urological function (OPEN) study protocol [ISRCTN54195799]. Nutr J. 2011:10:22.

25. Mayen AL, Marques-Vidal P, Paccaud F, Bovet P, Stringhini S Socioeconomic determinants of dietary patterns in low- and middleincome countries: a systematic review. Am J Clin Nutr. 2014;100(6):1520-31

26. Amarya S, Singh K, Sabharwal M. Changes during aging and their association with malnutrition. J Clin Gerontol Geriatr. 2015;6(3):7884.

27. Nalado AM, Mahlangu JN, Waziri B, Duarte R, Paget G, Olorunfemi G, et al. Ethnic prevalence of anemia and predictors of anemia among chronic kidney disease patients at a tertiary hospital in Johannesburg, South Africa. Int J Nephrol Renov Dis. 2019;12:19-32.

28. Jelkmann W. Regulation of erythropoietin production. J Physiol 2011;589(Pt 6):1251-8.

29. Roy CN. Anemia in frailty. Clin Geriatr Med. 2011 Feb 1;27(1):67 78 .

30. Poggiali E, Migone De Amicis M, Motta I. Anemia of chronic disease: a unique defect of iron recycling for many different chronic diseases. Eur J Intern Med. 2014;25(1):12-7. 